\title{
Risk factors for hospital morbidity and mortality after the Norwood procedure: A report from the Pediatric Heart Network Single Ventricle Reconstruction trial
}

\author{
Sarah Tabbutt, MD, PhD, ${ }^{a}$ Nancy Ghanayem, MD, ${ }^{\mathrm{b}}$ Chitra Ravishankar, MD, ${ }^{\mathrm{a}}$ Lynn A. Sleeper, $\mathrm{ScD},{ }^{\mathrm{c}}$ \\ David S. Cooper, MD, MPH, ${ }^{d}$ Deborah U. Frank, MD, PhD, ${ }^{\mathrm{e}}$ Minmin Lu, MS, ${ }^{\mathrm{c}}$ Christian Pizarro, MD, ${ }^{\mathrm{f}}$ \\ Peter Frommelt, MD, ${ }^{\mathrm{b}}$ Caren S. Goldberg, MD, ${ }^{\mathrm{g}}$ Eric M. Graham, MD, ${ }_{\mathrm{h}}$ Catherine Dent Krawczeski, MD, ${ }^{\mathrm{i}}$ \\ Wyman W. Lai, MD, ${ }^{\mathrm{j}}$ Alan Lewis, MD, ${ }^{\mathrm{k}}$ Joel A. Kirsh, MD, ${ }^{1}$ Lynn Mahony, MD, ${ }^{\mathrm{m}}$ Richard G. Ohye, MD, ${ }^{\mathrm{g}}$ \\ Janet Simsic, MD,${ }^{\mathrm{n}}$ Andrew J. Lodge, MD,${ }^{\mathrm{o}}$ Ellen Spurrier, $\mathrm{MD},{ }^{\mathrm{f}}$ Mario Stylianou, $\mathrm{PhD},{ }^{\mathrm{p}}$ and \\ Peter Laussen, $\mathrm{MD},{ }^{\mathrm{q}}$ for the Pediatric Heart Network Investigators
}

\begin{abstract}
Objectives: We sought to identify risk factors for mortality and morbidity during the Norwood hospitalization in newborn infants with hypoplastic left heart syndrome and other single right ventricle anomalies enrolled in the Single Ventricle Reconstruction trial.

Methods: Potential predictors for outcome included patient- and procedure-related variables and center volume and surgeon volume. Outcome variables occurring during the Norwood procedure and before hospital discharge or stage II procedure included mortality, end-organ complications, length of ventilation, and hospital length of stay. Univariate and multivariable Cox regression analyses were performed with bootstrapping to estimate reliability for mortality.

Results: Analysis included 549 subjects prospectively enrolled from 15 centers; 30 -day and hospital mortality were $11.5 \%$ (63/549) and $16.0 \%$ (88/549), respectively. Independent risk factors for both 30-day and hospital mortality included lower birth weight, genetic abnormality, extracorporeal membrane oxygenation (ECMO) and open sternum on the day of the Norwood procedure. In addition, longer duration of deep hypothermic circulatory arrest was a risk factor for 30-day mortality. Shunt type at the end of the Norwood procedure was not a significant risk factor for 30-day or hospital mortality. Independent risk factors for postoperative renal failure $(n=46)$, sepsis $(n=93)$, increased length of ventilation, and hospital length of stay among survivors included genetic abnormality, lower center/surgeon volume, open sternum, and post-Norwood operations.
\end{abstract}

Conclusions: Innate patient factors, ECMO, open sternum, and lower center/surgeon volume are important risk factors for postoperative mortality and/or morbidity during the Norwood hospitalization. (J Thorac Cardiovasc Surg 2012;144:882-95)

Risk factors for hospital morbidity and mortality after the Norwood procedure for patients with hypoplastic left heart syndrome (HLHS) have been reported from single centers and multicenter databases. Many centers report low birth weight, genetic abnormalities, restrictive atrial septum, duration of cardiopulmonary bypass (CPB), and extracorporeal membrane oxygenation (ECMO) as risk factors for

\footnotetext{
From the Children's Hospital of Philadelphia, ${ }^{a}$ Philadelphia, Pa; Children's Hospital of Wisconsin and Medical College of Wisconsin, ${ }^{\mathrm{b}}$ Milwaukee, Wis; New England Research Institutes, ${ }^{\mathrm{c}}$ Watertown, Mass; Congenital Heart Institute of Florida, ${ }^{\mathrm{d}}$ St Petersburg, Fla; Primary Children's Medical Center and the University of Utah, ${ }^{\text {e }}$ Salt Lake City, Utah; Nemours Cardiac Center, ${ }^{\mathrm{f}}$ Wilmington, Del; University of Michigan Medical School, ${ }^{\mathrm{g}}$ Ann Arbor, Mich; Medical University of South Carolina, ${ }^{\text {h }}$ Charleston, SC; Cincinnati Children's Medical Center, ${ }^{\text {i }}$ Cincinnati, Ohio; Morgan Stanley Children's Hospital of New York Presbyterian, ${ }^{j}$ New York, NY; Children's Hospital Los Angeles, ${ }^{k}$ Los Angeles, Calif; Hospital for Sick Children, ${ }^{1}$ Toronto, Ontario, Canada; University of Texas Southwestern Medical Center, ${ }^{\mathrm{m}}$ Dallas, Tex; Emory University, ${ }^{\mathrm{n}}$ Atlanta, Ga; North Carolina Consortium: Duke University, ${ }^{\circ}$ Durham, NC; National Heart, Lung, and Blood Institute, ${ }^{\mathrm{p}}$ Bethesda, Md; and Children's Hospital Boston, ${ }^{\mathrm{q}}$ Boston, Mass.

Supported by grants from the National Heart, Lung, and Blood Institute (HL068269, HL068270, HL068279, HL068281, HL068285, HL068292, HL068290,
}

mortality. ${ }^{1-14}$ Multicenter reports have shown higher mortality at smaller volume centers. ${ }^{2,15,16}$

The Pediatric Heart Network Single Ventricle Reconstruction (SVR) trial provides a unique opportunity to analyze prospectively collected preoperative, operative, and postoperative data in the largest cohort of newborn infants with HLHS and other single right ventricle anomalies to date.

HL068288, HL085057). This work is solely the responsibility of the authors and does not necessarily represent the official views of the NHLBI.

Disclosures: Authors have nothing to disclose with regard to commercial support. Dr Tabbutt's current affiliation is University of California San Francisco Benioff Children's Hospital, San Francisco, Calif; Dr Cooper's current affiliation is Cincinnati Children's Medical Center, Cincinnati, Ohio; and Dr Simsic's current affiliation is Nationwide Children's Hospital, Columbus, Ohio.

Clinical Trial Registration No. NCT00115934.

Received for publication Nov 7, 2011; revisions received March 21, 2012; accepted for publication May 9, 2012; available ahead of print June 18, 2012.

Address for reprints: Sarah Tabbutt, MD, PhD, University of California San Francisco

Benioff Children's Hospital, Moffitt 680, 555 Parnassus Ave, San Francisco, CA 94143 (E-mail: tabbutts@peds.ucsf.edu).

$0022-5223 / \$ 36.00$

Copyright (C) 2012 by The American Association for Thoracic Surgery doi:10.1016/j.jtcvs.2012.05.019 


\section{Abbreviations and Acronyms \\ $\mathrm{CPB}=$ cardiopulmonary bypass \\ $\mathrm{CPR}=$ cardiopulmonary resuscitation \\ DHCA $=$ deep hypothermic circulatory arrest \\ $\mathrm{ECMO}=$ extracorporeal membrane oxygenation \\ $\mathrm{E}-\mathrm{CPR}=\mathrm{ECMO}$ required to restore circulation during CPR \\ HLHS = hypoplastic left heart syndrome \\ MBTS $=$ modified Blalock-Taussig shunt \\ $\mathrm{RCP}=$ regional cerebral perfusion \\ RVPAS $=$ right ventricular-pulmonary artery shunt \\ SVR $=$ Single Ventricle Reconstruction}

Primary results of the SVR trial reported differences in outcome between subjects undergoing the Norwood procedure with a right ventricular-pulmonary artery shunt (RVPAS) versus a modified Blalock-Taussig shunt (MBTS). ${ }^{17}$ The initial report focused solely on the comparative outcomes relative to shunt type. The primary aim of this prespecified secondary analysis was to examine the associations of patient-related risk factors and perioperative management variables on morbidity and mortality during the Norwood hospitalization. To facilitate comparisons with previous reports of surgical morality for the Norwood procedure, we analyzed both 30-day and hospital mortality. Our secondary aim was to explore associations with shunt type on longerterm transplant-free survival in subjects requiring cardiopulmonary resuscitation (CPR) and/or ECMO.

\section{METHODS}

\section{Study Design}

Details of the SVR trial design have been previously published. ${ }^{17,18}$ In brief, inclusion criteria consisted of a diagnosis of HLHS or other single right ventricle anomaly and a planned Norwood procedure. Patients were excluded if the preoperative cardiac anatomy rendered either the MBTS or RVPAS technically impossible or if they had any major congenital or acquired extracardiac abnormality that could independently decrease the likelihood of transplant-free survival at 1 year of age. Subjects were randomly assigned to receive either the MBTS or the RVPAS. The institutional review board at each center approved the protocol. Written informed consent was obtained from a parent/guardian before randomization. Other than the type of shunt placed, the remainder of the perioperative care was per institutional standard. For the purposes of this analysis, subjects were categorized by the shunt in place at the end of the Norwood procedure.

\section{Data Collection and Definitions}

Data were prospectively collected. The 16 outcome variables are defined in Appendix Table 1. Other than 30-day mortality, outcomes were recorded if they occurred before hospital discharge or before stage II procedure for subjects not discharged. ECMO initiated after the Norwood procedure was considered an outcome variable. The 42 potential risk factors are defined in Appendix Table 2. Subjects underwent genetic evaluations when indicated by clinical suspicion of a genetic abnormality. In addition, a research option for a genetic evaluation was offered. Preoperative shock was defined as a composite of hepatic failure (Appendix Table 1), renal failure (Appendix Table 1), lactate greater than $10 \mathrm{mmol} / \mathrm{L}$, or intubation for shock. Perfusion strategies included deep hypothermic circulatory arrest (DHCA) alone or regional cerebral perfusion (RCP) with or without DHCA. Open sternum included all subjects with an open sternum on the day of the Norwood procedure. These subjects were categorized as those at a "routine" center where sternums of all patients were left open at the end of the Norwood procedure or those at an "elective" center where the surgeon selectively decided to leave the patient's sternum open. ECMO for failure to separate from CPB was examined as a potential risk factor. The day of Norwood procedure was defined as day 1 .

The longer-term outcome of patients requiring CPR (defined as receiving chest compressions) and/or ECMO was examined in further detail. Subjects were characterized as follows: CPR alone (CPR), ECMO alone (ECMO), ECMO required to restore circulation during CPR (E-CPR), and neither CPR nor ECMO ("none"). For the subanalysis of these 4 groups, only CPR, ECMO, or E-CPR occurring within 30 days of Norwood procedure were included. Subjects requiring ECMO for failure to separate from CPB were included in the ECMO group.

\section{Statistical Methods}

Summary statistics include mean \pm standard deviation, median, and range. We analyzed 2 mortality outcomes: (1) time to death up to discharge from the Norwood hospitalization, using Kaplan-Meier estimation and Cox proportional hazards regression, with censoring at dates of cardiac transplant and at time of stage II procedure (for those not discharged) and (2) a dichotomous 30-day post-Norwood procedure mortality indicator, using logistic regression. We analyzed 4 continuous outcomes using linear regression: post-Norwood right ventricular fractional area change, logtransformed time to initial extubation, log-transformed total days ventilated, and log-transformed hospital length of stay. Subjects who died or underwent cardiac transplant during the hospitalization were excluded from analysis of the extubation, ventilation, and length of stay outcomes. We analyzed 10 dichotomous morbidity outcomes using logistic regression; for 3 of these (necrotizing enterocolitis, liver failure, mediastinitis), only univariate analyses were conducted owing to the low event rate. For construction of multivariable models, variables with a $P$ value $\leq .2$ in univariate analysis were used as candidate predictors in regression modeling. The $R^{2}$ and maximum rescaled $R^{2}$ values are reported for linear and logistic regression models, respectively. In addition, generalized additive modeling was used to identify nonlinear associations between outcomes and continuous candidate predictors. Variables with a nonlinearity $P$ value $<.05$ were considered in the multivariable selection procedure. Bootstrap resampling was used to estimate the reliability of each factor selected by stepwise regression for the multivariable mortality model. ${ }^{19,20}$ We retained a term in the model if it had reliability greater than $50 \%$ and a $P$ value of less than .05 .

We used analysis of variance and the Kruskal-Wallis test for comparison of the distributions of baseline characteristics across the 4 ECMO/CPR groups. To account for potential survival bias in this secondary analysis of CPR with or without ECMO subjects, we used Cox proportional hazards regression with a time-dependent group indicator to model time to death or transplant, using all available follow-up data. A test of interaction between subject group and shunt type was used to assess differential treatment effect by group.

\section{RESULTS}

Between May 2005 and July 2008 there were 549 evaluable SVR subjects: 268 with an MBTS and 281 with an RVPAS.

\section{Mortality}

Mortality during the Norwood hospitalization was $16 \%$ (88/549). Deaths occurred at a median of 16 days, (range, 


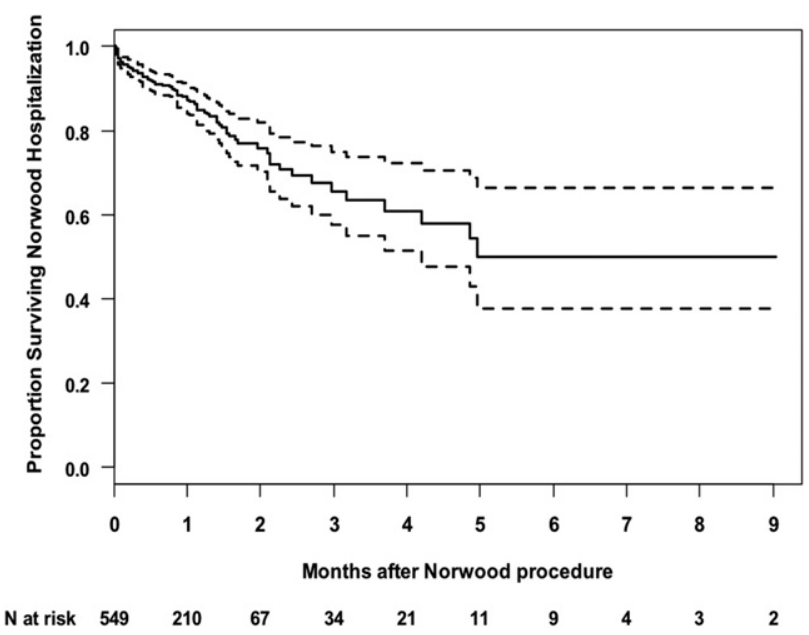

FIGURE 1. Kaplan-Meier estimates and pointwise $95 \%$ confidence bands for hospital survival after the Norwood procedure $(\mathrm{N}=549)$. Patients were censored when they were transplanted $(n=9)$ or discharged $(\mathrm{n}=430)$.

1-149 days). The 30-day mortality was $12 \%$ (63/549). Figure 1 shows the Kaplan-Meier survival curve for all subjects during the Norwood hospitalization. Included among the survivors were 9 subjects who underwent cardiac transplantation before discharge; median time to transplant was 51 days after the Norwood procedure (range, 9-270 days). There were 22 subjects who remained in the hospital until the stage II procedure; median time to stage II procedure was 116 days (range, 49-271 days).

Significant risk factors by univariate analysis for 30-day mortality included the following: lower birth weight, lower gestational age, genetic abnormality, duration of DHCA, duration of total support time, ECMO for failure to separate from $\mathrm{CPB}$, open sternum at the Norwood procedure, and surgeon Norwood volume. Additional risk factors by univariate analysis for Norwood hospital mortality included preoperative intervention on the atrial septum and younger age at surgery. Significant risk factors by multivariable analysis, for 30-day and hospital mortality, are shown in Table 1. Shunt type was not a significant risk factor for mortality. ECMO and open sternum on the day of the Norwood procedure were the strongest risk factors for mortality. ECMO was initiated during the Norwood procedure in $8 \%$ of subjects with open sternum and $1 \%$ of subjects with closed sternum $(P=.002)$. Open sternum remained a significant risk factor for mortality with ECMO included in the multivariable model. Sternums were routinely left open in all patients at 7 centers (median hospital mortality, 18\%; range, $2 \%-39 \%$ ) and sternums were electively left open at 8 centers (median hospital mortality, 13\%; range, 0\%-30\%). The 7 routine open sternum centers represented $59 \%$ (244/415) of the subjects with open sternum. The mortality risk of open sternum did not differ significantly between routine and elective centers. For the open sternum cohort, reliability by bootstrapping methodology for hospital mortality was high at $90 \%$. Although subjects with the anatomic subtype of mitral stenosis with aortic atresia were more likely to require ECMO during the Norwood procedure $(13 \%$ vs $4 \% ; P<.001)$, mitral stenosis with aortic atresia was not an independent risk factor for 30-day $(P=.23)$ or hospital (hazard ratio, $1.48 ; 95 \%$ confidence interval, 0.92-2.36; $P=.1$ ) mortality.

\section{Morbidity}

Results of multivariable analyses for the morbidity outcomes are shown in Table 2. Shunt type was only an independent risk factor for CPR (odds ratio, 2.02; $P=.005$ ) and decreased ventricular function as measured by postoperative echocardiographic fractional area change (odds ratio, $-3.59 ; P<.001)$ with the MBTS compared with the RVPAS. Genetic abnormality, center volume, surgeon volume, open sternum, and post-Norwood operations were the most common independent risk factors for postNorwood morbidities.

TABLE 1. Independent risk factors for 30-day and hospital mortality after the Norwood procedure

\begin{tabular}{|c|c|c|c|c|c|c|c|}
\hline \multirow[b]{2}{*}{ Candidate predictor } & \multicolumn{3}{|c|}{ Thirty-day mortality } & \multicolumn{4}{|c|}{ Hospital mortality } \\
\hline & Odds ratio & $95 \% \mathrm{CI}$ & $\boldsymbol{P}$ & Hazard ratio & $95 \% \mathrm{CI}$ & $P$ & Reliability \\
\hline Birth weight, $\mathrm{kg}$ & 0.52 & $(0.29,0.94)$ & .03 & 0.62 & $(0.41,0.93)$ & .02 & $63 \%$ \\
\hline Genetic abnormality & & & $<.001$ & & & $<.001$ & $81 \%$ \\
\hline Yes & 2.93 & $(0.78,10.9)$ & & 2.89 & $(1.21,6.9)$ & & \\
\hline No & Ref & & & Ref & & & \\
\hline Unknown & 13.6 & $(6.23,29.5)$ & & 6.42 & $(3.67,11.2)$ & & \\
\hline DHCA duration, $\min$ & 1.10 & $(1.03,1.19)$ & .01 & & & & \\
\hline ECMO at Norwood procedure & 4.38 & $(1.76,10.9)$ & .002 & 3.41 & $(1.94,5.98)$ & $<.001$ & $69 \%$ \\
\hline Open sternum & & & $<.001$ & & & .002 & $90 \%$ \\
\hline Yes, routine site & 18.1 & $(5.17,63.4)$ & & 5.87 & $(2.22,15.6)$ & & \\
\hline Yes, elective site & 5.81 & $(1.75,19.3)$ & & 4.25 & $(1.65,10.6)$ & & \\
\hline No, elective site & Ref & & & Ref & & & \\
\hline
\end{tabular}


TABLE 2. Multivariable models for morbidity outcomes after the Norwood procedure

\begin{tabular}{|c|c|c|c|c|c|}
\hline Outcome & $\begin{array}{l}\text { No. of subjects } \\
\text { with event }\end{array}$ & $\begin{array}{l}\text { Time to event, days; } \\
\text { median (range) }\end{array}$ & $\begin{array}{l}\text { Odds } \\
\text { ratio }\end{array}$ & $95 \% \mathrm{CI}$ & $\boldsymbol{P}$ \\
\hline Catheter intervention $\left(R^{2}=7 \%\right)$ & 27 & $27(2-129)$ & & & \\
\hline Preoperative intubation for apnea/transport & & & 0.23 & $(0.05,0.97)$ & .05 \\
\hline Left atrial decompression & & & 4.02 & $(1.19,13.6)$ & .03 \\
\hline Regional cerebral perfusion & & & 2.11 & $(1.04,4.29)$ & .04 \\
\hline Central nervous system injury $\left(R^{2}=4 \%\right)$ & 38 & $5(1-157)$ & & & \\
\hline Genetic abnormality & & & & & .01 \\
\hline Yes & & & 2.84 & $(1.29,6.28)$ & \\
\hline No & & & Ref & & \\
\hline Unknown & & & 2.68 & $(1.27,5.64)$ & \\
\hline Renal failure $\left(R^{2}=26 \%\right)$ & 46 & $3(1-77)$ & & & \\
\hline Anomalous pulmonary venous return & & & 10.2 & $(2.43,42.4)$ & .002 \\
\hline Preoperative intubation for apnea/transport & & & 3.46 & $(1.66,7.21)$ & $<.001$ \\
\hline Heart block & & & 18.8 & $(5.05,70)$ & $<.001$ \\
\hline Open sternum & & & & & .02 \\
\hline Yes, routine site & & & 7.61 & $(1.86,31.2)$ & \\
\hline Yes, elective site & & & 6.72 & $(1.62,27.9)$ & \\
\hline No, elective site & & & Ref & & \\
\hline Surgeon Norwood volume & & & & & .006 \\
\hline$\leq 5 / y$ & & & 0.31 & $(0.09,1.09)$ & \\
\hline 6 to $\leq 10 / y$ & & & 0.90 & $(0.28,2.91)$ & \\
\hline 11 to $\leq 15 / y$ & & & 0.20 & $(0.06,0.61)$ & \\
\hline$>15 / y$ & & & Ref & & \\
\hline Center volume & & & & & .02 \\
\hline$\leq 15 / \mathrm{y}$ & & & 1.55 & $(0.53,4.58)$ & \\
\hline 16 to $\leq 20 / y$ & & & 0.44 & $(0.14,1.45)$ & \\
\hline 21 to $\leq 15 / y$ & & & 0.32 & $(0.11,0.91)$ & \\
\hline$>30 / y$ & & & Ref & & \\
\hline Sepsis $\left(R^{2}=16 \%\right)$ & 93 & $19(1-133)$ & & & \\
\hline Gestational age, wk & & & 0.79 & $(0.68,0.92)$ & .002 \\
\hline AS/MS/VSD & & & 3.81 & $(1.05,13.9)$ & .04 \\
\hline Duration of DHCA, min & & & 1.07 & $(1.004,1.13)$ & .04 \\
\hline Open sternum duration, $\mathrm{d}$ & & & 1.08 & $(1.05,1.12)$ & $<.001$ \\
\hline Center volume & & & & & .003 \\
\hline$\leq 15 / y$ & & & 2.28 & $(1.17,4.47)$ & \\
\hline 16 to $\leq 20 / y$ & & & 0.94 & $(0.40,2.19)$ & \\
\hline 21 to $\leq 30 / y$ & & & 0.64 & $(0.33,1.26)$ & \\
\hline$>30 / y$ & & & Ref & & \\
\hline ECMO after Norwood procedure $\left(R^{2}=40 \%\right)$ & 56 & $2(1-149)$ & & & \\
\hline Birth weight $<2.5 \mathrm{~kg}$ & & & & & .04 \\
\hline Yes & & & 2.38 & $(1.04,5.44)$ & \\
\hline No & & & Ref & & \\
\hline Age at Norwood procedure, $\mathrm{d}$ & & & 0.87 & $(0.78,0.98)$ & .02 \\
\hline Operations after Norwood procedure & & & 2.23 & $(1.84,2.69)$ & $<.01$ \\
\hline $\operatorname{CPR}\left(R^{2}=25 \%\right)$ & 97 & $5(1-149)$ & & & \\
\hline Birth weight, kg & & & 0.54 & $(0.34,0.85)$ & .008 \\
\hline Genetic abnormality & & & & & $<.001$ \\
\hline Yes & & & 0.32 & $(0.17,0.62)$ & \\
\hline No & & & 0.28 & $(0.16,0.49)$ & \\
\hline Unknown & & & Ref & & \\
\hline Shunt & & & & & .005 \\
\hline MBTS & & & 2.02 & $(1.23,3.32)$ & \\
\hline RVPAS & & & Ref & & \\
\hline Operations after Norwood procedure & & & 1.51 & $(1.32,1.73)$ & $<.001$ \\
\hline
\end{tabular}




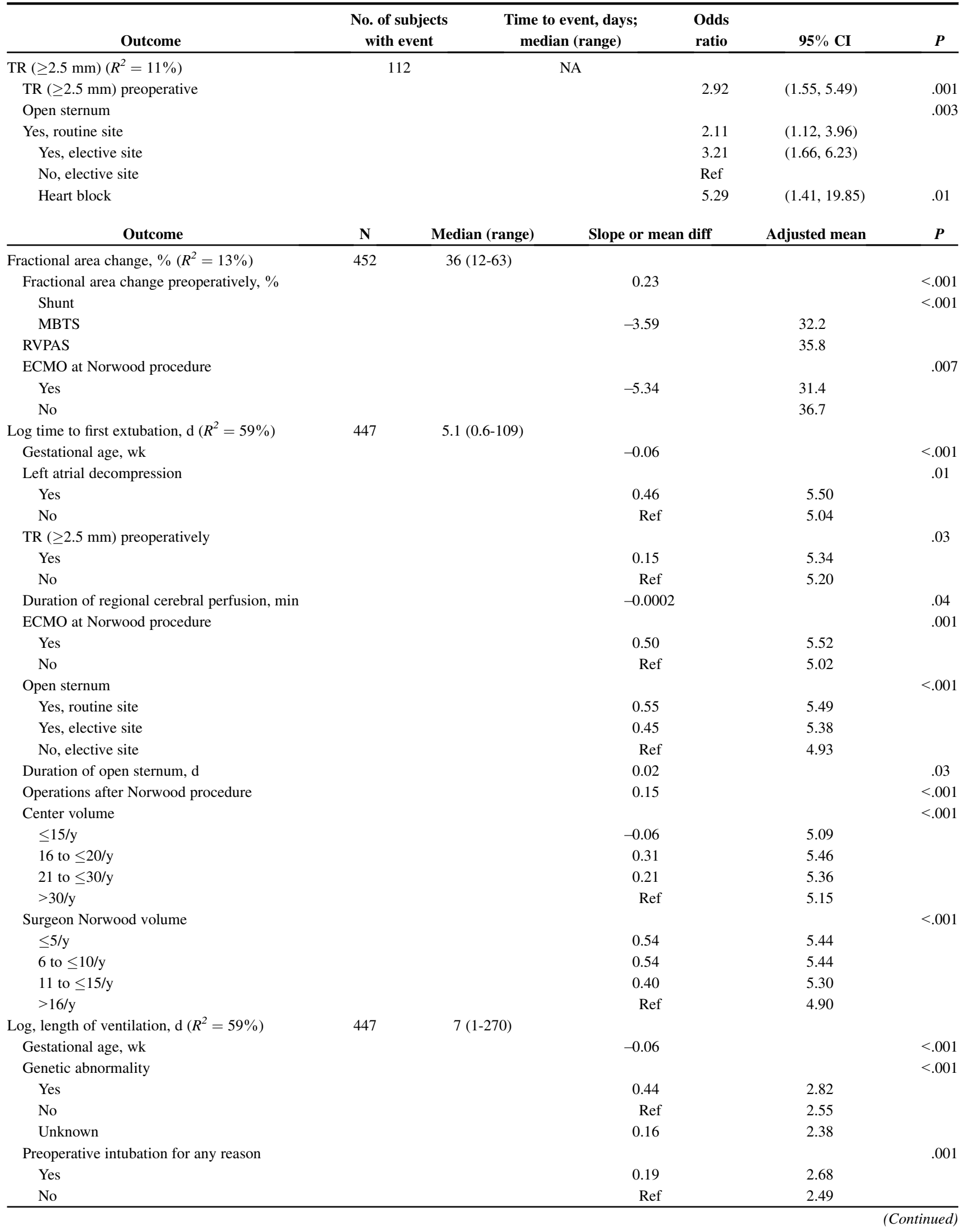


TABLE 2. Continued

\begin{tabular}{|c|c|c|c|c|c|}
\hline Outcome & $\mathbf{N}$ & Median (range) & Slope or mean diff & Adjusted mean & $\boldsymbol{P}$ \\
\hline Left atrial decompression & & & & & .02 \\
\hline Yes & & & 0.49 & 2.83 & \\
\hline No & & & Ref & 2.34 & \\
\hline Preoperative shock & & & & & .02 \\
\hline Yes & & & 0.27 & 2.72 & \\
\hline No & & & Ref & 2.45 & \\
\hline TR $(\geq 2.5 \mathrm{~mm})$ preoperatively & & & & & .004 \\
\hline Yes & & & 0.24 & 2.70 & \\
\hline No & & & Ref & 2.47 & \\
\hline Age at Norwood procedure, $\mathrm{d}$ & & & -0.02 & & .02 \\
\hline Open sternum & & & & & .006 \\
\hline Yes, routine site & & & 0.25 & 2.69 & \\
\hline Yes, elective site & & & 0.20 & 2.63 & \\
\hline No, elective site & & & Ref & 2.43 & \\
\hline Operations after Norwood procedure & & & 0.34 & & $<.001$ \\
\hline Center volume & & & & & .005 \\
\hline$\leq 15 / y$ & & & 0.004 & 2.49 & \\
\hline 16 to $\leq 20 / y$ & & & 0.26 & 2.75 & \\
\hline 21 to $\leq 30 / y$ & & & 0.12 & 2.61 & \\
\hline$>30 / y$ & & & Ref & 2.49 & \\
\hline Surgeon Norwood volume & & & & & .008 \\
\hline$\leq 5 / y$ & & & 0.33 & 2.71 & \\
\hline 6 to $\leq 10 / y$ & & & 0.27 & 2.65 & \\
\hline 11 to $\leq 15 / y$ & & & 0.21 & 2.59 & \\
\hline$>16 / y$ & & & Ref & 2.38 & \\
\hline Log, hospital length of stay, $\mathrm{d}\left(R^{2}=49 \%\right)$ & 452 & $24(6-270)$ & & & \\
\hline Birth weight, $\mathrm{kg}$ & & & -0.01 & & .03 \\
\hline Genetic abnormality & & & & & .007 \\
\hline Yes & & & 0.33 & 3.78 & \\
\hline No & & & Ref & 3.44 & \\
\hline Unknown & & & 0.06 & 3.5 & \\
\hline Preoperative intubation for shock & & & & & .009 \\
\hline Yes & & & 0.15 & 3.66 & \\
\hline No & & & Ref & 3.5 & \\
\hline $\mathrm{TR}(\geq 2.5 \mathrm{~mm})$ preoperative & & & & & .04 \\
\hline Yes & & & 0.15 & 3.65 & \\
\hline No & & & Ref & 3.5 & \\
\hline Duration of DHCA, min & & & & & .003 \\
\hline$\leq 45 \min$ & & & -0.017 & 3.49 & \\
\hline$>45 \min$ & & & Ref & 3.66 & \\
\hline Operations after Norwood procedure & & & 0.27 & & $<.001$ \\
\hline Center volume & & & & & $<.001$ \\
\hline$\leq 15 / y$ & & & 0.16 & 3.62 & \\
\hline 16 to $\leq 20 / y$ & & & 0.34 & 3.8 & \\
\hline 21 to $\leq 30 / y$ & & & -0.03 & 3.43 & \\
\hline$>30 / y$ & & & Ref & 3.46 & \\
\hline
\end{tabular}

$C I$, Confidence interval; Ref, reference group; $A S / M S / V S D$, aortic stenosis, mitral stenosis, ventricular septal defect; $D H C A$, deep hypothermic circulatory arrest; $E C M O$, extracorporeal membrane oxygenation; $C P R$, cardiopulmonary resuscitation; MBTS, modified Blalock-Taussig; RVPAS, right ventricle-pulmonary artery shunt; $T R$, tricuspid regurgitation; $N A$, not available; Diff, difference.

Less frequent morbidities were explored by univariate analyses. Hepatic failure occurred in 16 subjects at a median of 22 days (range, 2-159 days) after the Norwood procedure. Fifty percent (8/16) of the subjects with hepatic failure died before discharge. Significant risk factors for hepatic failure included lower birth weight $(P=.02)$, aortic atresia
$(P=.03)$, MBTS $(P=.04)$, longer support time $(P=.05)$, and heart block on the day of the Norwood procedure $(P=.02)$. Mediastinitis occurred in 15 subjects at a median of 8 days (range, 3-35 days) after the Norwood procedure. Significant risk factors for mediastinitis included preoperative intubation for apnea or transport $(P=.04)$, RVPAS 
TABLE 3. Baseline characteristics of subjects requiring ECMO, CPR, E-CPR, or neither interventions (none) within the first 30 days after Norwood procedure

\begin{tabular}{|c|c|c|c|c|c|}
\hline Variable & CPR (37) & ECMO (49) & E-CPR (36) & None (427) & $\boldsymbol{P}$ \\
\hline Birth weight, $\mathrm{kg}$ & $2.89 \pm .7$ & $3.12 \pm .6$ & $2.95 \pm .6$ & $3.13 \pm .5$ & .09 \\
\hline Birth weight $<2.5 \mathrm{~kg}$ & $10(27 \%)$ & $9(18 \%)$ & $11(31 \%)$ & $46(11 \%)$ & $<.001$ \\
\hline Gestational age, wk & $37.6 \pm 2.1$ & $38.2 \pm 1.7$ & $37.9 \pm 1.5$ & $38.2 \pm 1.6$ & .20 \\
\hline Age at Norwood procedure, $\mathrm{d}$ & $6.2 \pm 3.6$ & $5.0 \pm 3.0$ & $4.8 \pm 2.8$ & $5.9 \pm 4.3$ & .11 \\
\hline Ascending aorta, $\mathrm{mm} *$ & $3.1 \pm 1.4$ & $2.8 \pm 1.5$ & $2.9 \pm 1.8$ & $3.2 \pm 1.8$ & .27 \\
\hline $\mathrm{TR} \geq 2.5 \mathrm{~mm}$, preoperative $\dagger$ & $3(9 \%)$ & $3(6 \%)$ & $4(13 \%)$ & $25(6 \%)$ & .47 \\
\hline $\begin{array}{l}\text { Fractional area change, } \\
\text { preoperative, } \% \ddagger\end{array}$ & $49 \pm 11$ & $46 \pm 8$ & $47 \pm 8$ & $46 \pm 9$ & .34 \\
\hline \multicolumn{6}{|c|}{ Incidence of event within shunt type } \\
\hline MBTS (268) & $23(9 \%)$ & $27(10 \%)$ & $22(8 \%)$ & $196(73 \%)$ & \\
\hline RVPAS (281) & $14(5 \%)$ & $22(8 \%)$ & $14(5 \%)$ & $231(82 \%)$ & \\
\hline$P$ & .13 & .37 & .17 & & \\
\hline
\end{tabular}

$E C M O$, Extracorporeal membrane oxygenation; $C P R$, cardiopulmonary resuscitation; $E-C P R$, ECMO required to restore circulation during CPR; $T R$, tricuspid regurgitation; MBTS, modified Blalock Taussig shunt; RVPAS, right ventricular to pulmonary artery shunt. *Ascending aorta size by surgeon observation. †Sample sizes for TR are CPR, 31; ECMO, 48; E-CPR, 35; None, 392. ‡Sample sizes for fractional area change are CPR, 30; ECMO, 45; E-CPR, 34; None, 394.

$(P=.04)$, and heart block on the day of the Norwood procedure $(P=.02)$. Open sternum was not a risk factor for mediastinitis. Necrotizing enterocolitis occurred in 14 subjects at a median of 22.5 days (range, 2-66 days) after the Norwood procedure. No significant risk factors were identified.

\section{ECMO and CPR}

Of the 549 evaluable subjects, $22 \%(122 / 549)$ received CPR $(n=37)$, ECMO $(n=49)$, or E-CPR $(n=36)$ within the first 30 days after the Norwood procedure and $78 \%$ (427/549) did not require these interventions ("none"). Important baseline characteristics among the 4 groups are shown in Table 3. Within the ECMO, CPR, and E-CPR

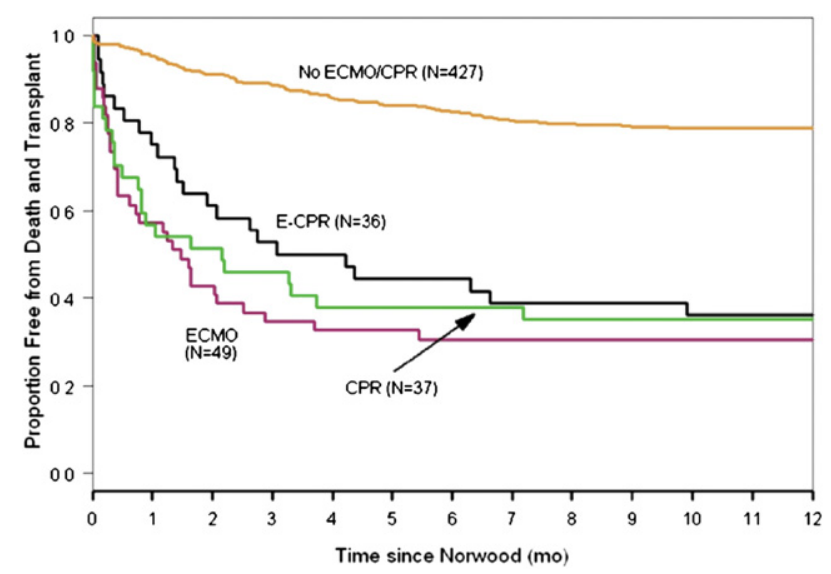

FIGURE 2. Kaplan-Meier estimates for transplant-free survival after the Norwood procedure using all available follow-up (mean, $2.7 \pm 0.9$ years for survivors). Group classification is according to extracorporeal membrane oxygenation $(E C M O)$, cardiopulmonary resuscitation $(C P R)$, ECMO required to restore circulation during CPR ( $E-C P R)$, and none of these interventions (none) within the first 30 days after the Norwood procedure. groups, there was no difference in the number of subjects according to shunt type. After the Norwood procedure, the mean time to initiation of CPR was $3.1 \pm 1.4$ days, ECMO was $1.1 \pm 1.7$ days, and E-CPR was $4.7 \pm 5.9$ days. Within the ECMO subjects, $71 \%$ (35/49) required ECMO for failure to separate from CPB. Low birth weight was more common in the CPR and E-CPR groups $(P<.001)$.

Longer-term survival for these subjects was examined with a mean follow-up of $2.7 \pm 0.9$ years. Subjects receiving CPR, ECMO, or E-CPR had a lower transplant-free survival $(P<.0001$; Figure 2$)$. The 2-year transplant-free survival was $35 \%$ for CPR, $26 \%$ for ECMO, $30 \%$ for E-CPR, and $75 \%$ for the "none" group. The impact of shunt type on transplant-free survival within the 4 groups

TABLE 4. Association of shunt type with transplant-free survival within the 4 groups: CPR, ECMO, E-CPR and neither intervention (none)

\begin{tabular}{lcccc}
\hline & $\begin{array}{c}\text { Hazard } \\
\text { ratio }\end{array}$ & $\mathbf{9 5 \%} \mathbf{C I}$ & $\boldsymbol{P}$ & $\begin{array}{c}\text { Interaction } \\
\text { * }\end{array}$ \\
\hline Without adjustment & & & & \\
$\quad$ MBTS vs RVPAS & & & & \\
$\quad$ CPR & 1.28 & $(0.89,1.84)$ & .94 & .48 \\
$\quad$ ECMO & 0.82 & $(0.43,1.58)$ & .55 & .15 \\
E-CPR & 0.62 & $(0.28,1.36)$ & .23 & .06 \\
$\quad$ None & 1.42 & $(0.98,2.06)$ & .07 & \\
Adjustment for birth weight & & & & \\
$\quad$ and surgeon & & & & \\
MBTS vs RVPAS & & & & \\
$\quad$ CPR & 1.3 & $(0.54,3.16)$ & .56 & .74 \\
$\quad$ ECMO & 0.67 & $(0.33,1.36)$ & .26 & .05 \\
$\quad$ E-CPR & 0.48 & $(0.21,1.11)$ & .09 & .01 \\
$\quad$ None & 1.54 & $(1.04,2.28)$ & .03 & \\
\hline
\end{tabular}

$\overline{E C M O}$, Extracorporeal membrane oxygenation; $C P R$, cardiopulmonary resuscitation; $E-C P R$, ECMO required to restore circulation during CPR; $C I$, confidence interval; MBTS, modified Blalock-Taussig shunt; RVPAS, right ventricle-pulmonary artery shunt. $* P$ value from test of interaction of shunt type and therapy group versus none. 
is shown in Table 4. Subjects who did not require CPR or ECMO had better survival with an RVPAS. After adjustment for surgeon and birth weight, subjects with an MBTS had a better outcome after E-CPR or ECMO relative to subjects with an RVPAS compared with those subjects in the "none" group. This differential effect of shunt type was not observed for the CPR group in comparison with the "none" group.

\section{DISCUSSION}

The primary outcome of the SVR trial demonstrated a transplant-free survival benefit for subjects receiving an RVPAS, which was statistically significant at 12 months of age but no longer significant at longer follow-up (32 \pm 11 months). ${ }^{17}$ This prespecified secondary analysis reports the most extensive evaluation of risk factors for morbidity and mortality during the Norwood hospitalization in a multicenter cohort of newborn infants with HLHS and other single right ventricular anomalies to date. Multivariable analysis showed that only birth weight, genetic abnormality, ECMO, and open sternum at the Norwood procedure were independent risk factors for 30-day and hospital mortality, and the duration of DHCA was an independent risk factor for 30-day mortality.

Early outcomes for patients with HLHS have improved substantially over the past 3 decades. Reports of early postoperative mortality are predominantly from centers achieving excellent outcomes with reported surgical survivals of $81 \%$ to $93 \% .^{3,4,7-13}$ Results from multiple centers have been limited to database extraction with lower survivals of $72 \%$ to $78 \% .^{2,15,16}$ Reported risk factors for early mortality after the Norwood procedure differ among centers and include patient-related factors such as prematurity, ${ }^{10}$ lower birth weight, ${ }^{2-4,7}$ and presence of genetic or noncardiac abnormalities ${ }^{3,10}$; anatomic factors such as mitral stenosis/aortic atresia, ${ }^{14}$ smaller ascending aorta, ${ }^{2}$ restrictive atrial septum, or significant tricuspid regurgitation $^{4,7}$; preoperative factors such as shock $^{7}$ and $\mathrm{ECMO}^{10}$; operative factors such as older age at surgery, ${ }^{2}$ shunt type, ${ }^{11}$ longer $\mathrm{DHCA},{ }^{2} \mathrm{CPB}$, or total support time $^{4,14}$; and postoperative factors such as $\mathrm{ECMO}^{1,4,6,14}$ and low mixed venous saturation. ${ }^{13}$ An earlier surgical era $^{13}$ and lower center surgical volume ${ }^{2,15,16}$ have also been associated with early mortality. Differences in reported risk factors between centers may reflect variation among centers, variation in patient populations, or studies with small patient populations.

Of the independent risk factors that we identified for hospital mortality after the Norwood procedure, lower birth weight, genetic abnormality, longer duration of DHCA, and ECMO have been previously reported. We did not find the type of shunt by non-intention-to-treat analysis to be a significant risk factor for either 30-day or Norwood hospital mortality. These findings are consistent with the initial SVR trial report in which using intention-to-treat analysis, death, or transplant occurred within 30 days of the Norwood procedure in 10\% (28/274) of subjects with an RVPAS compared with $14 \%$ (38/275) with an MBTS. ${ }^{17}$ We did not find aortic atresia, size of the ascending aorta, or preoperative shock significant by univariate analysis. Prematurity, restrictive atrial septum requiring intervention, mitral stenosis/aortic atresia, moderate/severe tricuspid regurgitation, younger age at surgery, longer total support time, and lower center HLHS or surgeon Norwood volume were significant or marginally significant by univariate analysis in our study; however, they were not found to be risk factors for early mortality on multivariable analysis.

Open sternum remained significantly associated with hospital and 30-day mortality after adjusting for other important independent risk factors including ECMO for failure to separate from CPB. Open sternum remained a significant risk factor for mortality independent of the center's strategy (elective vs routine sternal closure). Few conflicting reports address open sternum as a risk factor for mortality. 7,21 Examination of the Society of Thoracic Surgeons Congenital Database $(\mathrm{n}=1283,45$ centers $)$ found $74 \%$ of patients undergoing Norwood procedure for HLHS were managed with an open sternum. ${ }^{22}$ Surgical mortality did not differ between centers with a high versus a low proportion of patients with an open sternum. In addition to mortality, we found open sternum to be an independent risk factor for postoperative renal failure, moderate to severe tricuspid regurgitation, longer time to first extubation, and duration of ventilation. We found the duration of open sternum to be a risk factor for sepsis, although importantly, not for mediastinitis. The practice of elective sternal closure is subject to selection bias; the patients chosen to have the sternum closed at the Norwood procedure were likely considered to be at lower risk for a poor outcome. In addition, the practice of open sternum may serve as a surrogate for variability in center clinical practices, which were not measured in this study. The decision to close the sternum in this trial was influenced by multiple factors, including the center's preference, the surgeon's assessment, and the use of ECMO with transthoracic cannulation. Thus, it is not possible to infer causality between open sternum and mortality. However, the significantly lower mortality among patients who had their chest closed at the conclusion of the Norwood procedure suggests that sternal closure can be performed safely in selected patients.

Although many centers have reported risk factors for surgical or hospital mortality after the Norwood procedure, analysis of risk factors for less frequent morbidities has been challenging owing to small sample sizes. We found a low $(<3 \%)$ incidence of necrotizing enterocolitis, hepatic failure, and mediastinitis. Central nervous system injury, renal failure, ECMO, and CPR occurred early with the median time to event less than 1 week after surgery. Hepatic 
failure, necrotizing enterocolitis, catheter intervention, and sepsis tended to occur later in the postoperative course.

The impact of center volume on mortality after the Norwood procedure has been reported. ${ }^{15,16}$ However, this study is the first multicenter report to include both center and surgeon volumes in the risk analysis. Using the Kids' Inpatient Database (2003, $\mathrm{n}=624$ patients, 60 centers), lower institutional HLHS volume was shown to be a significant risk factor for Norwood hospital mortality. ${ }^{15}$ Confounding variables included in the analysis were limited. More recently, using the Society of Thoracic Surgeons Congenital Heart Surgery Database (2011, n = 2557, 53 centers), lower center Norwood procedure volume was associated with higher hospital mortality. ${ }^{16}$ We did not find center HLHS or surgeon Norwood volume to be risk factors for 30-day or hospital mortality. This may reflect the different variables included in each analysis. In our analysis, if the operative variable of open sternum is not divided into elective and routine centers, then center volume remains in the model as an independent risk factor for hospital mortality. We did find volume to be a significant risk factor for several important morbidities. Lower surgeon Norwood volume was a risk factor for renal failure, longer time to first extubation, and duration of ventilation; lower center HLHS volume was a risk factor for sepsis, longer time to first extubation, duration of ventilation, and hospital length of stay.

Innate patient variables made up a majority of the independent risk factors we identified for morbidity and mortality with a few risk factors potentially modifiable. Perhaps designating a regional HLHS center could increase center/ surgeon volume. Routine preoperative intubation for transport and apnea may be unnecessary and can potentially be avoided with a lower dose of prostaglandin. Lower gestational age may be avoided by discouraging elective delivery before 39 weeks. $^{23}$

The need for $\mathrm{CPR}^{24}$ and $\mathrm{ECMO}^{1,4,6}$ is a serious morbidity for infants with HLHS. Most commonly, ECMO is reserved for extremely low cardiac output, profound hypoxemia, or inability to regain spontaneous circulation with CPR. Early survival after ECMO in newborn infants with HLHS is reported at $17 \%$ to $54 \%{ }^{1,6,13,25}$ We found a low transplant-free survival for subjects requiring ECMO, CPR, and E-CPR with attrition continuing for months after Norwood procedure. Of note, the survival of subjects requiring E-CPR did not differ from that of subjects placed on ECMO for either failure to separate from bypass or clinical deterioration without CPR. Our data did not enable us to report the subset of patients placed on ECMO for acute shunt failure, a subgroup reported to have better survival $(83 \%-100 \%))^{1,6}$ Similar to previous reports, we found improved survival after CPR alone for the RVPAS subjects. ${ }^{24}$ In contrast, we found that in subjects requiring ECMO or E-CPR, the MBTS was associated with a more favorable outcome.

\section{Limitations}

As study participation was limited to 15 participating centers, performing 5 or more Norwood procedures annually, the inferences cannot be generalized to centers with smaller case volumes. The only variable randomly assigned was shunt type. Patients with a potentially higher risk of mortality independent of a planned Norwood procedure may be excluded by study criteria. Some subjects died before postoperative echocardiography, which could bias these outcome measures. Formal genetic evaluation was not obtained for all subjects, weakening the potential strength of this candidate predictor. Genetic abnormality was the only significant risk factor for central nervous system injury, which could reflect ascertainment bias inasmuch as these subjects were more likely to undergo cranial imaging. Finally, we did not examine interactions between all possible risk factors. There may be selected subgroups with higher or lower risk for Norwood mortality or certain morbidities that were not identified.

\section{CONCLUSIONS}

In a large, multicenter prospective cohort of newborn infants with HLHS and related right ventricular anomalies undergoing the Norwood procedure as subjects of the SVR trial, we found lower birth weight, genetic abnormality, ECMO for failure to separate from CPB, and open sternum to be independent risk factors for 30-day and hospital mortality. Longer duration of DHCA was an independent risk factor for 30-day mortality. Shunt type was not found to be an independent risk factor for Norwood hospital mortality or morbidity outcomes with the exception that subjects with an MBTS had decreased ventricular function on postoperative echocardiography and increased odds of CPR. Patients requiring CPR and/or ECMO after the Norwood procedure have significantly lower transplant-free survival and remain at risk for attrition remote from the initial event. Although most risk factors were innate patient variables, potentially modifiable risk factors might include preoperative intubation, lower gestational age, elective open sternum, and center/surgeon volume.

\footnotetext{
References

1. Allan CK, Thiagarajan R, del Nido PJ, Roth SJ, Almodovar MC, Laussen PC. Indication for initiation of mechanical circulatory support impacts survival of infants with shunted single-ventricle circulation supported with extracorporeal membrane oxygenation. J Thorac Cardiovasc Surg. 2007; 133:660-7.

2. Ashburn DA, McCrindle BW, Tchervenkov CI, Jacobs ML, Lofland GK, Bove EL, et al. Outcomes after the Norwood operation in neonates with critical aortic stenosis or aortic valve atresia. J Thorac Cardiovasc Surg. 2003;125:1070-82.

3. Stasik CN, Goldberg CS, Bove EL, Devaney EJ, Ohye RG. Current outcomes and risk factors for the Norwood procedure. J Thorac Cardiovasc Surg. 2006;131:412-7.
} 
4. Gaynor JW, Mahle WT, Cohen MI, Ittenbach RF, DeCampli WM, Steven JM, et al. Risk factors for mortality after the Norwood procedure. Eur J Cardiothorac Surg. 2002;22:82-9.

5. Glatz JA, Tabbutt S, Gaynor JW, Rome JJ, Montenegro L, Spray TL, et al. Hypoplastic left heart syndrome with atrial level restriction in the era of prenatal diagnosis. Ann Thorac Surg. 2007;84:1633-9.

6. Ravishankar C, Dominguez TE, Kreutzer J, Wernovsky G, Marino BS, Godinez R, et al. Extracorporeal membrane oxygenation after stage I reconstruction for hypoplastic left heart syndrome. Pediatr Crit Care Med. 2006; 7:319-23.

7. Tabbutt S, Dominguez TE, Ravishankar C, Marino BS, Gruber PJ, Wernovsky G, et al. Outcomes after the stage I reconstruction comparing the right ventricular to pulmonary artery conduit with the modified Blalock Taussig shunt. Ann Thorac Surg. 2005;80:1582-91.

8. Cua CL, Thiagarajan RR, Gauvreau K, Lai L, Costello JM, Wessel DL, et al. Early postoperative outcomes in a series of infants with hypoplastic left heart syndrome undergoing stage I palliation operation with either modified Blalock-Taussig shunt or right ventricle to pulmonary artery conduit. Pediatr Crit Care Med. 2006; 7:238-44.

9. Mahle W, Cuadrado A, Tam VK. Early experience with a modified Norwood procedure using right ventricle to pulmonary artery conduit. Ann Thorac Surg. 2003; 76:1084-8.

10. Jacobs JP, Obrien SM, Chai PJ, Morell VO, Lindberg HL, Quintessenza JA. Management of 239 patients with hypoplastic left heart syndrome and related malformations from 1993 to 2007. AnnThorac Surg. 2008;85:1691-7.

11. Pizarro C, Malec E, Maher KO, Januszewska K, Gidding AA, Murdison KA, et al. Right ventricle to pulmonary artery conduit improves outcome after stage 1 Norwood for hypoplastic left heart syndrome. Circulation. 2003;108(Suppl 1): II155-60.

12. Sano S, Huang S, Kasahara S, Yoshizumi K, Kotani Y, Ishino K. Risk factors for mortality after the Norwood procedure using right ventricle to pulmonary artery shunt. Ann Thorac Surg. 2009;87:178-86.

13. Tweddell JS, Ghanayem NS, Mussatto KA, Mitchell ME, Lamers LJ, Musa NL, et al. Mixed venous oxygen saturation monitoring after stage 1 palliation for hypoplastic left heart syndrome. Ann Thorac Surg. 2007;84:1301-11.
14. Vida VL, Bacha EA, Larrazabal A, Gauvreau K, Dorfman AL, Marx G, et al. Surgical outcome for patients with the mitral stenosis-aortic atresia variant of hypoplastic left heart syndrome. J Thorac Cardiovasc Surg. 2008;135:339-46.

15. Hirsch JC, Gurney JG, Donohue JE, Gebremariam A, Bove EL, Ohye R. Hospital mortality for Norwood and arterial switch operations as a function of institutional volume. Pediatr Cardiol. 2007;29:713-7.

16. Pasquali SK, Jacobs JP, Xe H, Hornik CP, Jaquiss RDB, Jacobs ML, et al. The complex relationship between center volume and outcome inpatients undergoing the Norwood operation. Ann Thorac Surg. 2012;93:1556-62.

17. Ohye RG, Sleeper LA, Mahony L, Newburger JW, Pearson GD, Lu M, et al. Comparison of shunt types in the Norwood procedure for single-ventricle lesions. N Engl J Med. 2010;362:1980-92.

18. Ohye RG, Gaynor JW, Ghanayem NS, Goldberg CS, Laussen PC, Frommelt PC et al. Design and rationale of a randomized trial comparing the Blalock-Taussig and right ventricle-pulmonary artery shunts in the Norwood procedure. $J$ Thorac Cardiovasc Surg. 2008;136:968-75.

19. Breiman L. Bagging predictors. Machine Learning. 1996;24:123-40.

20. Efron B, Tibshiriani RJ. An introduction to the bootstrap. Boca Raton (FL): CRC Press LLC; 1998.

21. Alexi-Meskishvili V, Weng Y, Uhlemann F, Lange PE, Hetzer R. Prolonged open sternotomy after pediatric open heart operation: experience with 113 patients. Ann Thorac Surg. 1995;59:379-83.

22. Johnson JN, Jaggers J, Li S, O’Brien SM, Li JS, Jacobs JP, et al. Center variation and outcomes associated with delayed sternal closure after stage 1 palliation for hypoplastic left heart syndrome. J Thorac Cardiovasc Surg. 2010;139:1205-10.

23. Costello JM, Polito A, Brown DW, McElrath TF, Graham DA, Thiagarajan RR, et al. Birth before 39 weeks' gestation is associated with worse outcomes in neonates with heart disease. Pediatrics. 2010;126:e277-84.

24. Graham EM, Forbus GA, Bradley SM, Shirali GS, Atz AM. Incidence and outcome of cardiopulmonary resuscitation in patients with shunted single ventricle: advantage of right ventricle to pulmonary artery shunt. $J$ Thorac Cardiovasc Surg. 2006;131:e7-8.

25. Hintz SR, Benitz WE, Colby CE, Sheehan AM, Rycus P, Van Meurs KP, ELSO Registry. Utilization and outcomes of neonatal cardiac extracorporeal life support: 1996-2000. Pediatr Crit Care Med. 2005;6:33-8. 
APPENDIX TABLE 1. Outcome variables after the Norwood procedure

\begin{tabular}{|c|c|c|c|}
\hline Outcome & $\mathbf{N}$ & $\mathbf{n}$ & Definition/comment \\
\hline Mortality, 30 day & 549 & 63 & Includes 4 subjects who died after discharge \\
\hline Hospital mortality & 549 & 88 & $\begin{array}{l}\text { Mortality during or after the Norwood procedure until discharge or } \\
\text { stage II operation }\end{array}$ \\
\hline Necrotizing enterocolitis & 549 & 14 & Defined as pneumatosis intestinalis or free air \\
\hline Hepatic failure & 549 & 16 & AST, ALT, GGT >500 units \\
\hline Mediastinitis & 549 & 15 & $\begin{array}{l}\text { Deep sternal wound infection demonstrating sternal instability or } \\
\text { requiring surgical incision and drainage }\end{array}$ \\
\hline Catheter intervention & 549 & 38 & $\begin{array}{l}\text { Transcatheter interventions (38 subjects) included: balloon dilation } \\
\text { and/or stent of shunt (14), balloon dilation and/or stent of branch } \\
\text { pulmonary artery (5), balloon dilation of the aorta (2), balloon } \\
\text { dilation of the aortic valve (1), atrial radiofrequency ablation (1), } \\
\text { innominate artery stent (3), device placed (1) and multiple } \\
\text { interventions (11) }\end{array}$ \\
\hline Central nervous system injury & 549 & 47 & $\begin{array}{l}\text { Defined as intracranial bleed or stroke confirmed by imaging, } \\
\text { clinical or EEG seizure. Imaging was per clinical team }\end{array}$ \\
\hline Renal failure & 549 & 46 & $\begin{array}{l}\text { Creatinine }>1.5 \mathrm{mg} / \mathrm{dL} \text {, tripling of creatinine over }<7 \text { days or } \\
\text { dialysis }\end{array}$ \\
\hline Sepsis & 549 & 93 & Confirmed positive blood culture \\
\hline ECMO after Norwood procedure & 549 & 56 & $\begin{array}{l}\text { Postoperative ECMO, excluding patients placed on ECMO during } \\
\text { Norwood procedure }\end{array}$ \\
\hline CPR & 549 & 97 & $\begin{array}{l}\text { Postoperative CPR (defined as chest compressions), excluding CPR } \\
\text { during Norwood procedure }\end{array}$ \\
\hline Fractional area change & 452 & & Predischarge ECHO \\
\hline $\mathrm{TR} \geq 2.5 \mathrm{~mm}$ & 471 & 112 & Predischarge ECHO showing TR jet $\geq 2.5 \mathrm{~mm}$ on one of two views \\
\hline Log time to first extubation, $\mathrm{d}$ & 447 & & $\begin{array}{l}\text { Deaths (88) and transplants (9) were excluded. Five subjects had } \\
\text { insufficient data. Log transformed data was used for analyses }\end{array}$ \\
\hline Log length of ventilation, $d$ & 451 & & $\begin{array}{l}\text { Deaths (88) and transplants (9) were excluded. One subject had } \\
\text { insufficient data. Log transformed data was used for analyses }\end{array}$ \\
\hline Log hospital length of stay, $d$ & 452 & & $\begin{array}{l}\text { Discharge includes subjects transferred to other institutions. } \\
\text { Subjects who died (88) or were transplanted (9) were excluded. } \\
\text { Log transformed data was used for analyses. }\end{array}$ \\
\hline
\end{tabular}

$N$, Number of patients in analysis; $n$, number of patients with outcome; $A S T$, aspartate aminotransferase; $A L T$, alanine transaminase; $G G T$, gamma-glutamyl transpeptidase; $E E G$, electroencephalogram; $E C M O$, extracorporeal membrane oxygenation; $C P R$, cardiopulmonary resuscitation; $E C H O$, echocardiogram; $T R$, tricuspid regurgitation. 
APPENDIX TABLE 2. Candidate predictors

\begin{tabular}{|c|c|c|c|c|}
\hline Candidate predictor & $\mathbf{N}$ & $\mathbf{n}$ & Mean \pm SD & Definition/comment \\
\hline \multicolumn{5}{|l|}{ Patient characteristics } \\
\hline Prenatal diagnosis & 549 & 421 & & \\
\hline Birth weight, kg & 549 & & $3.1 \pm 0.5$ & \\
\hline Birth weight $<2.5 \mathrm{~kg}$ & 549 & 76 & & \\
\hline Gestational age, wk & 549 & & $38 \pm 1.6$ & \\
\hline Gestational age $<37$ wk & 549 & 64 & & \\
\hline Genetic abnormality & 549 & & & \\
\hline Yes & & 29 & & $\begin{array}{l}\text { Yes, abnormal chromosomes only (3), genetic syndrome only (21), } \\
\text { genetic syndrome and abnormal chromosomes (5) }\end{array}$ \\
\hline No & & 344 & & $\begin{array}{l}\text { No, normal chromosomes and formal genetic evaluation found no } \\
\text { syndrome }\end{array}$ \\
\hline Unknown & & 176 & & Unknown, subjects without chromosomes or genetic evaluation \\
\hline \multirow[t]{4}{*}{ Nonsyndromic anomalies } & 374 & 268 & & None \\
\hline & & 38 & & 1 \\
\hline & & 25 & & 2 \\
\hline & & 43 & & $\geq 3$ \\
\hline Genetic abnormality and/or nonsyndromic anomalies & 549 & & & \\
\hline Yes & & 120 & & \\
\hline No & & 253 & & \\
\hline \multirow[t]{2}{*}{ Unknown } & & 176 & & \\
\hline & & 176 & & \\
\hline \multicolumn{5}{|l|}{ Preoperative } \\
\hline Preoperative intubation, any & 547 & 263 & & Intubation, for any reason \\
\hline Preoperative intubation for apnea/transport & 547 & 101 & & \\
\hline Preoperative intubation for shock & 547 & 117 & & Intubation for shock, respiratory failure or acidosis \\
\hline Preoperative left atrial decompression & 549 & 21 & & $\begin{array}{l}\text { Intervention on atrial septum for obstructed pulmonary venous } \\
\text { return }\end{array}$ \\
\hline Preoperative surgical intervention & 549 & 8 & & $\begin{array}{l}\text { Non-cardiac surgical interventions: bowel surgery (2), chest tube } \\
\text { (2), other (4) }\end{array}$ \\
\hline Preoperative bloodstream infection & 549 & 8 & & \\
\hline Preoperative central nervous system injury & 549 & 14 & & $\begin{array}{l}\text { Defined as seizure, stroke or intracranial bleed confirmed by } \\
\text { imaging }\end{array}$ \\
\hline Preoperative shock & 547 & 38 & & $\begin{array}{l}\text { See Appendix Table } 2 . \text { Hepatic failure (6), renal failure (10), } \\
\text { elevated lactate (23), or intubation for shock (14) }\end{array}$ \\
\hline \multicolumn{5}{|l|}{ Preoperative echocardiogram } \\
\hline Left ventricular cavity present & 359 & 254 & & \\
\hline Fractional area change preoperatively, $\%$ & 503 & & $35 \pm 8.6$ & RV fractional area change \\
\hline $\mathrm{TR} \geq 2.5 \mathrm{~mm}$ preoperatively & 506 & 471 & & $\begin{array}{l}\text { Width of the tricuspid regurgitation jet } \geq 2.5 \mathrm{~mm} \text { in either } \mathrm{AP} \text { or } \\
\text { lateral view }\end{array}$ \\
\hline Aortic stenosis & 537 & 226 & & Flow through aortic valve \\
\hline \multicolumn{5}{|l|}{ Anatomy } \\
\hline Aortic atresia & 549 & 345 & & \\
\hline MS/AA & 549 & 138 & & Mitral stenosis, aortic atresia. Mortality analyses only \\
\hline MS/AS/IVS & 549 & 45 & & Mitral stenosis, aortic stenosis with intact ventricular septum \\
\hline MS/AS/VSD & 549 & 11 & & Mitral stenosis, aortic stenosis with ventricular septal defect \\
\hline Anomalous pulmonary venous return & 549 & 11 & & \\
\hline Ascending aorta diameter, observed, $\mathrm{cm}$ & 534 & & $0.32 \pm 0.17$ & Surgeon observed \\
\hline Ascending aorta diameter, echocardiogram, $\mathrm{cm}$ & 534 & & $0.36 \pm 0.18$ & \\
\hline \multicolumn{5}{|l|}{ Operative } \\
\hline Age at Norwood procedure, $\mathrm{d}$ & 549 & & $5.8 \pm 4.1$ & \\
\hline Shunt & 549 & & & $\begin{array}{l}\text { Shunt in place at the end of the Norwood procedure. MBTS } 268 \text {, } \\
\text { RVPAS } 281\end{array}$ \\
\hline
\end{tabular}




\begin{tabular}{|c|c|c|c|c|}
\hline Candidate predictor & $\mathbf{N}$ & $\mathbf{n}$ & Mean \pm SD & Definition/comment \\
\hline Regional cerebral perfusion & 544 & & & Perfusion strategy unknown (5) \\
\hline Yes & & 247 & & RCP alone (36), with DHCA (211) \\
\hline No & & 297 & & \\
\hline Duration of DHCA, min & 544 & & $31.7 \pm 23.2$ & Subjects managed with no DHCA were included as 0 minutes \\
\hline Duration of DHCA $>10 \mathrm{~min}$ & 414 & & $40.4 \pm 19.5$ & Duration of DHCA: DHCA alone (297) RCP with DHCA (117) \\
\hline Duration of regional cerebral perfusion, min & 546 & & $23.7 \pm 29.2$ & $\begin{array}{l}\text { Subjects managed with DHCA (297) alone were included as } \\
0 \text { minutes. }\end{array}$ \\
\hline Duration of RCP, excluding DHCA alone, min & 249 & & $51.9 \pm 20.1$ & \\
\hline Total support time, $\min$ & 549 & & $143 \pm 54.1$ & Inclusive of $\mathrm{CPB}, \mathrm{DHCA}$, and $\mathrm{RCP}$ \\
\hline ECMO at Norwood procedure & 549 & 35 & & $\begin{array}{l}\text { ECMO during Norwood procedure for failure to separate from } \\
\text { bypass }\end{array}$ \\
\hline \multicolumn{5}{|l|}{ Perioperative } \\
\hline Heart block & 549 & 13 & & $\begin{array}{l}\text { Second- or third-degree heart block in ICU on day of Norwood } \\
\text { procedure }\end{array}$ \\
\hline Open sternum & 544 & & & Open sternum on day of Norwood procedure \\
\hline Yes, routine site & & 244 & & All sternums left open at routine site \\
\hline Yes, elective site & & 171 & & Elective site with selective decision to leave sternum open \\
\hline No, elective site & & 129 & & Elective site with selective decision to close sternum \\
\hline Duration of open sternum, $\mathrm{d}$ & 549 & 538 & $4.7 \pm 6.4$ & $\begin{array}{l}\text { Thirty-four subjects died with open sternum and date of death was } \\
\text { used. Subjects with closed sternum were included as 0. Eleven had } \\
\text { missing data }\end{array}$ \\
\hline Operations after Norwood procedure & 549 & 429 & & $\begin{array}{l}\text { Subjects with additional surgical procedures (cardiac or other) after } \\
\text { the Norwood procedure and before discharge }\end{array}$ \\
\hline \multicolumn{5}{|r|}{ 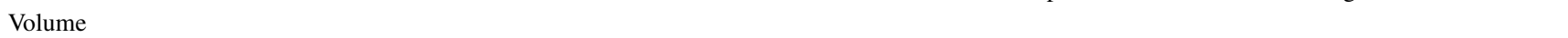 } \\
\hline Center volume & 549 & & & Patients with single RV screened per center per year \\
\hline$\leq 15$ & & 93 & & \\
\hline 16 to $\leq 20$ & & 109 & & \\
\hline 21 to $\leq 30$ & & 176 & & \\
\hline$>30$ & & 171 & & \\
\hline Surgeon Norwood volume & 549 & & & $\begin{array}{l}\text { Patients with single RV scheduled for Norwood procedure screened } \\
\text { per surgeon per year }\end{array}$ \\
\hline$\leq 5$ & & 108 & & \\
\hline 6 to $\leq 10$ & & 113 & & \\
\hline 11 to $\leq 15$ & & 239 & & \\
\hline$>15$ & & 89 & & \\
\hline
\end{tabular}

$N$, Number of subjects for which the data were available; $n$, number of subjects with a predictor or number of subjects in each category; $S D$, standard deviation; $R V$, right ventricle (ventricular); $A P$, anteroposterior; $M B T S$, modified Blalock-Taussig shunt; $R V P A S$, right ventricular-pulmonary artery shunt; $R C P$, regional cerebral perfusion; $D H C A$, deep hypothermic circulatory arrest; $C P B$, cardiopulmonary bypass; $E C M O$, extracorporeal membrane oxygenation; $I C U$, intensive care unit. 


\section{APPENDIX TABLE 3. Pediatric Heart Network Investigators}

National Heart, Lung, and Blood Institute: Gail Pearson, Victoria Pemberton, Rae-Ellen Kavey,* Mario Stylianou, Marsha Mathis.*

Network Chair: University of Texas Southwestern Medical Center, Lynn Mahony.

Data Coordinating Center: New England Research Institutes, Lynn Sleeper (PI), Sharon Tennstedt (PI), Steven Colan, Lisa Virzi,* Patty Connell,* Victoria Muratov, Lisa Wruck, * Minmin Lu, Dianne Gallagher, Anne Devine, ${ }^{*}$ Julie Schonbeck, Thomas Travison, ${ }^{*}$ David F. Teitel.

Core Clinical Site Investigators: Children's Hospital Boston, Jane W. Newburger (PI), Peter Laussen, Pedro del Nido, Roger Breitbart, Jami Levine, Ellen McGrath, Carolyn Dunbar-Masterson, John E. Mayer, Jr., Frank Pigula, Emile A. Bacha, Francis Fynn-Thompson; Children's Hospital of New York, Wyman Lai (PI), Beth Printz,* Daphne Hsu, William Hellenbrand, Ismee Williams, Ashwin Prakash, * Seema Mital,* Ralph Mosca,* Darlene Servedio,* Rozelle Corda, Rosalind Korsin, Mary Nash*; Children's Hospital of Philadelphia, Victoria L. Vetter (PI), Sarah Tabbutt,* J. William Gaynor (Study Co-Chair), Chitra Ravishankar, Thomas Spray, Meryl Cohen, Marisa Nolan, Stephanie Piacentino, Sandra DiLullo, ${ }^{*}$ Nicole Mirarchi; Cincinnati Children's Medical Center, D. Woodrow Benson (PI), Catherine Dent Krawczeski, Lois Bogenschutz, Teresa Barnard, Michelle Hamstra, Rachel Griffiths, Kathryn Hogan, Steven Schwartz,* David Nelson, Pirooz Eghtesady*; North Carolina Consortium: Duke University, East Carolina University, Wake Forest University, Page A. W. Anderson (PI)—deceased, Jennifer Li (PI), Wesley Covitz, Kari Crawford, * Michael Hines, James Jaggers, * Theodore Koutlas, Charlie Sang, Jr., Lori Jo Sutton, Mingfen Xu; Medical University of South Carolina, J. Philip Saul (PI), Andrew Atz, Girish Shirali, Scott Bradley, Eric Graham, Teresa Atz, Patricia Infinger; Primary Children's Medical Center and the University of Utah, Salt Lake City, Utah, L. LuAnn Minich (PI), John A. Hawkins, Michael Puchalski, Richard V. Williams, Peter C. Kouretas, Linda M. Lambert, Marian E. Shearrow, Jun A. Porter*; Hospital for Sick Children, Toronto, Brian McCrindle (PI), Joel Kirsh, Chris Caldarone, Elizabeth Radojewski, Svetlana Khaikin, Susan McIntyre, Nancy Slater; University of Michigan, Caren S. Goldberg (PI), Richard G. Ohye (Study Chair), Cheryl Nowak*; Children's Hospital of Wisconsin and Medical College of Wisconsin, Nancy S. Ghanayem (PI), James S. Tweddell, Kathleen A. Mussatto, Michele A. Frommelt, Peter C. Frommelt, Lisa Young-Borkowski.

Auxiliary Sites: Children's Hospital Los Angeles, Alan Lewis (PI), Vaughn Starnes, Nancy Pike; The Congenital Heart Institute of Florida (CHIF), Jeffrey P. Jacobs (PI), James A. Quintessenza, Paul J. Chai, David S. Cooper, J. Blaine John, James C. Huhta, Tina Merola, Tracey Grifith; Emory University, William Mahle (PI), Kirk Kanter, Joel Bond,* Jeryl Huckaby; Nemours Cardiac Center, Christian Pizarro (PI), Carol Prospero; Julie Simons, Gina Baffa, Wolfgang A. Radtke; University of Texas Southwestern Medical Center, Ilana Zeltzer (PI), Tia Tortoriello,* Deborah McElroy, Deborah Town.

Angiography Core Laboratory: Duke University, John Rhodes, J. Curt Fudge.

Echocardiography Core Laboratories: Children's Hospital of Wisconsin, Peter Frommelt; Children's Hospital Boston, Gerald Marx.

\section{APPENDIX TABLE 3. Continued}

Genetics Core Laboratory: Children's Hospital of Philadelphia, Catherine Stolle.

Protocol Review Committee: Michael Artman (Chair); Erle Austin; Timothy Feltes, Julie Johnson, Thomas Klitzner, Jeffrey Krischer, G. Paul Matherne.

Data and Safety Monitoring Board: John Kugler (Chair); Rae-Ellen Kavey, ${ }^{*}$ Executive Secretary; David J. Driscoll, Mark Galantowicz, Sally A. Hunsberger, Thomas J. Knight, Holly Taylor, Catherine L. Webb.*

PI, Principal investigator. *No longer at the institution listed. 